\title{
Clinicopathological significance of mitochondrial D-Loop mutations in head and neck carcinoma
}

\author{
A Lièvre', H Blons ${ }^{1,2}$, AM Houllier', O Laccourreye ${ }^{3}$, D Brasnu ${ }^{3}$, P Beaune $^{1,2}$ and P Laurent-Puig ${ }^{*, 1,2}$ \\ 'INSERM, U490, Université René Descartes, Paris F-75006, France; ${ }^{2}$ Assistance Publique-Hôpitaux de Paris, Hôpital Européen Georges Pompidou, \\ pôle biologie, Paris F-750 I5, France; ${ }^{3}$ Assistance Publique-Hôpitaux de Paris, Hôpital Européen Georges Pompidou, senvice d'Oto-Rhino-Laryngologie \\ et de Chirurgie cervico-faciale, Paris F-750 I5, France
}

Mitochondrial DNA mutations have been reported in several types of tumours, including head and neck squamous cell carcinoma (HNSCC). The noncoding region of the Displacement-Loop (D-Loop) has emerged as a mutational hotspot and we recently found that they were associated with prognosis and response to 5 fluorouracil (5FU) in colon cancers. In order to evaluate the frequence of D-Loop mutations in a large series of HNSCC and establish correlations with clinicopathologic parameters, we sequenced the D-Loop of 109 HNSCC before a treatment by neoadjuvant 5FU-cisplatin-based chemotherapy and surgery. Then, we correlated these mutations with prognosis and response to chemotherapy. A D-Loop mutation was identified in $21 \%$ of the tumors, the majority of them were located in a $C$-tract $(D 3 \mid 0)$. The prevalence of $D 310$ mutations increased significantly with the number of cytosines in the matched normal tissue sequence $(P=0.02)$. Hypopharyngeal cancer was significantly more frequent $(P=0.03)$ and tobacco consumption more important $(P=0.0 \mathrm{I})$ in the group of patients with $\mathrm{D}$-Loop mutation. The presence of D-Loop mutation was not associated with prognosis or with response to neoadjuvant chemotherapy. These results suggest that D-Loop mutations should be considered as a cancer biomarker that may be useful for the early detection of HNSCC in individuals at risk of this cancer.

British Journal of Cancer (2006) 94, 692-697. doi: I 0. I038/sj.bjc.6602993 www.bjcancer.com

Published online 21 February 2006

(c) 2006 Cancer Research UK

Keywords: mitochondrial DNA; mutation; head and neck cancer, tobacco; chemotherapy; prognosis

\begin{abstract}
Although much knowledge has been collected concerning alterations in cancer cell nuclear DNA (nDNA), less attention has been paid to mutations within mitochondrial DNA (mtDNA). Mitochondrial DNA is a 16569 bp double-stranded, circular DNA encoding 13 respiratory chain protein subunits, 22 tRNAs and two rRNAs. It is also composed of a $1.2 \mathrm{~kb}$ noncoding region, the Displacement-Loop (D-Loop), which contains essential transcription and replication elements. Owing to a particular susceptibility to oxidative damage due to high levels of reactive oxygen species (ROS) generation in mitochondria, inefficient DNA repair system and a lack of protective histones in this organelle, mutation rate has been reported to be 10-17-fold higher in the mtDNA than in the nDNA (Fliss et al, 2000). Mitochondria has long been suspected to be involved in carcinogenesis (Warburg, 1956). Its role in apoptosis supports this hypothesis (Zamzami and Kroemer, 2001) and it was shown that mtDNA mutations may lead to a dysregulation of oxidative phosphorylation that can enhance production of the carcinogenic ROS. Over last years, somatic mtDNA mutations have been reported in many human tumours (Polyak et al, 1998; Maximo et al, 2000; Richard et al, 2000; Yeh et al, 2000; Hibi et al, 2001b; Sanchez-Cespedes et al, 2001; Kirches
\end{abstract}

\footnotetext{
*Correspondence: Professor P Laurent-Puig, INSERM U490, Université René Descartes, 45 rue des Saints-Pères 75006, Paris, France; E-mail: pierre.laurent-puig@univ-paris5.fr

Received I5 December 2005; accepted 17 January 2006; published online 21 February 2006
}

et al, 2001; Liu et al, 2001; Lievre et al, 2005), including head and neck squamous cell carcinoma (HNSCC) that were found mutated in small series in $37-77 \%$ of the cases (Fliss et al, 2000; Sanchez-Cespedes et al, 2001; Ha et al, 2002; Tan et al, 2003; Poetsch et al, 2004). Although mutations may occur throughout the mitochondrial genome, the vast majority of them have been described in the noncoding region of the D-Loop and particularly in a mononucleotide repeat named D310 (C-tract, nucleotide position: $303-315)$ that has emerged as a mutational hotspot in HNSCC (Fliss et al, 2000; Sanchez-Cespedes et al, 2001; Ha et al, 2002; Tan et al, 2003; Poetsch et al, 2004).

Head and neck squamous cell carcinoma represents $5 \%$ of all newly diagnosed cancer cases in the northern and western Europe and in the US (Muir and Weiland, 1995) where it represents a public health problem. As in most solid tumours, head and neck tumor epithelial cells undergo nuclear genetic alterations in protooncogenes and tumour suppressor genes through a multistep process. One of the most frequent alterations are TP53 somatic mutations found in more than a half of the cases. Allelic losses are also frequently observed on 3p, 9p and 17p (Nawroz et al, 1994; van der Riet et al, 1994; Blons et al, 1999), as the amplification of the cyclin D1 oncogene. Identification of new genetic alterations associated with HNSCC is important since they may allow to better understand the molecular mechanisms involved in head and neck carcinogenesis and serve as a molecular marker that may be used in evaluating the tumorigenic potential of head and neck lesions in individuals at high risk of cancer. Recently, we found that D-Loop 
mutations were linked to prognosis and lack of benefit from 5 fluorouracil (5FU)-based adjuvant chemotherapy in colorectal carcinomas (Lievre et al, 2005). Neoadjuvant chemotherapy have been recently developed in new treatment strategies of locally advanced HNSCC and has been shown to be curative in complete clinical responder patients with a cancer of the pharyngolarynx (Laccourreye et al, 2001). Identification of molecular factors associated with response to neoadjuvant chemotherapy has become an important goal because it may help to select patients who could benefit from this treatment and so from a possible organ preservation. Therefore, the aims of this work were to determine the frequency of D-Loop mutations in a large series of HNSCC, establish correlations between D-Loop mutations and clinicopathologic parameters and determine the impact of these mutations on prognosis and response to neoadjuvant $5 \mathrm{FU}$-cisplatin-based chemotherapy in HNSCC patients.

\section{MATERIALS AND METHODS}

\section{Patients}

This study was performed on patients with histologically proven HNSCC managed at the Laennec Hospital (Paris, France) who had been prospectively included in a previous study in which response to neoadjuvant chemotherapy was assessed (Blons et al, 2004). The inclusion criteria retained were the following: no previous history of cancer, no multiple tumour locations, no contraindication for a 5FU- or cisplatin-based chemotherapy and indication for neoadjuvant chemotherapy prior to surgery or radiotherapy. This work was performed according to the French Law and blood samples and tumour biopsies were obtained after written informed consent and approval of the local ethic committee (CCPPRB-\#96,017). Among the 148 patients initially included, 109 (98 male and 11 female subjects, mean age: $57.8 \pm 1$ years) for whom DNA were still available were screened for mtDNA mutations. Tumours were located in the oral cavity $(n=13)$, the oropharynx $(n=46)$, the hypopharynx $(n=27)$ and the endolarynx $(n=23)$. They were classified according to the TNM classification and staged as recommended by the American Joint Committee on Cancer. There were five T1, $42 \mathrm{~T} 2,28 \mathrm{~T} 3,34 \mathrm{~T} 4$ tumours, and 49 tumours were N0 whereas 60 of them were $\mathrm{N}+$. Three tumours were stage I, 23 were stage II, 25 were stage III and 58 were stage IV. Among the patients, 63 smoked $>35$ pack-years; $34,15-35$ pack-years and 12 , $<15$ pack-years. A TP53 mutation was present in 72 patients $(67.3 \%)$. Clinicopathologic characteristics of the patients are listed in Table 1. All patients received a neoadjuvant chemotherapy before surgery or radiotherapy that consisted of cisplatin $\left(25 \mathrm{mg} \mathrm{m}^{-2}\right.$ day $\left.^{-1}\right)$ and $5 \mathrm{FU}\left(1 \mathrm{~g} \mathrm{~m}^{-2}\right.$ day $\left.^{-1}\right)$ delivered as a daily continuous i.v. dose in 4-day courses. Three courses were repeated at 16-21 days intervals. Clinical response was assessed as defined by the Eastern Cooperative Oncology Group. Responder patients (R) were defined by patients who showed at least a $50 \%$ decrease in tumour size and nonresponder patients (NR) by those who showed $<50 \%$ decrease in tumour size. In this series, 72 patients $(66.1 \%)$ were responders and 37 (33.9\%) were nonresponders.

\section{Tissue sample preparation and DNA extraction}

Tumour and $10 \mathrm{ml}$ of blood from each patient were collected at the initial diagnosis during endoscopy under general anesthesia. All tumour samples were diagnosed as invasive squamous-cell carcinoma after a histopathological analysis and then frozen in liquid nitrogen. Lymphocytes and tumour tissues samples were stored at $-80^{\circ} \mathrm{C}$ and extracted as described previously (Blons et al, 1999).

\section{Displacement-Loop amplification}

Polymerase chain reaction (PCR) amplification of the D-Loop was performed on a Gen Amp PCR System 9700 (Applied Biosystems,
Table I Clinicopathologic characteristics of HNSCC patients according to D-Loop mutation

\begin{tabular}{|c|c|c|c|c|}
\hline $\begin{array}{l}\text { Clinicopathologic } \\
\text { characteristics }\end{array}$ & $\begin{array}{c}\text { Number } \\
\text { of } \\
\text { patients }\end{array}$ & $\begin{array}{c}\text { Patients } \\
\text { with } \\
\text { mutated } \\
\text { tumour (\%) }\end{array}$ & $\begin{array}{c}\text { Patients } \\
\text { with } \\
\text { nonmutated } \\
\text { tumour (\%) }\end{array}$ & $P$-value \\
\hline Age (mean) & & $56.9 \pm 2$ & $58.0 \pm 1$ & 0.655 \\
\hline \multicolumn{5}{|l|}{ Gender } \\
\hline Male & $98(89.9)$ & $22(95.6)$ & $76(88.4)$ & \multirow[t]{2}{*}{0.3} \\
\hline Female & $11(10.1)$ & I (4.4) & $10(11.6)$ & \\
\hline \multicolumn{5}{|l|}{ Tumour sites } \\
\hline Oral cavity & $13(11.9)$ & I (4.4) & $12(13.9)$ & \multirow[t]{4}{*}{0.03} \\
\hline Oropharynx & $46(42.2)$ & $7(30.4)$ & $39(45.4)$ & \\
\hline Hypopharynx & $27(24.8)$ & II (47.8) & $16(18.6)$ & \\
\hline Endolarynx & $23(21.1)$ & $4(17.4)$ & $19(22.1)$ & \\
\hline \multicolumn{5}{|l|}{ Tumour stage } \\
\hline I & $3(2.8)$ & $2(8.7)$ & I (1.2) & \multirow[t]{4}{*}{0.24} \\
\hline$\|$ & $23(21.1)$ & $4(17.4)$ & $19(22.1)$ & \\
\hline III & $25(22.9)$ & $6(26.1)$ & $19(22.1)$ & \\
\hline IV & $58(53.2)$ & II (47.8) & $47(54.6)$ & \\
\hline $\begin{array}{l}\text { Tobacco (mean } \\
\text { pack-year) }\end{array}$ & & $48 \pm 3$ & $37 \pm 2$ & 0.01 \\
\hline \multicolumn{5}{|l|}{ TP53 mutation } \\
\hline Yes & $72(67.3)$ & $19(82.6)$ & $53(63.1)$ & \multirow[t]{2}{*}{0.07} \\
\hline No & $35(32.7)$ & $4(17.4)$ & $31(36.9)$ & \\
\hline \multicolumn{5}{|c|}{ Response to chemotherapy } \\
\hline Responder & $72(66.1)$ & $14(60.9)$ & $58(67.4)$ & \multirow[t]{3}{*}{0.55} \\
\hline Nonresponder & $37(33.9)$ & $9(39.1)$ & $28(32.6)$ & \\
\hline Total & $109(100)$ & 23 & 86 & \\
\hline
\end{tabular}

Foster City, CA, USA) using primers F47: 5'-CGC ACG GAC TAC AAC CAC GAC-3' (forward) and R15: $5^{\prime}$-CTG TGG GGG GTG TCT TTG GG (reverse) as described previously (Lievre et al, 2005). The $2467 \mathrm{bp}$ PCR products (nucleotide positions: 14679-577) were then purified using G-50 Sephadex superfine (Amersham Biosciences, Orsay, France) on Multiscreen support (Millipore, Bedford, MA, USA).

\section{Direct sequencing of the D310 repeat}

The D310 repeat sequencing was performed on a Gene Amp PCR System 9700 (Applied Biosystems) using a Big Dye Terminator cycle sequencing kit (Applied Biosystems) as described previously (Lievre et al, 2005). Sequences were analysed on an ABI Prism ${ }^{\circledR}$ 3900 DNA Analyser automated sequencer (Applied Biosystems). The results of DNA sequence analysis were compared with the published reference mtDNA sequence (GenBank, access number J01415) using Autoassembler ${ }^{\circledR}$ software (Applied Biosystems). A $400 \mathrm{bp}$ fragment of the D-Loop (nucleotide position: 190-590) containing the D310 homopolymeric C-tract from each patient was analysed. Any mtDNA sequences that differed between tumour and matched lymphocytes mtDNA were scored as somatic mutations. All somatic mutations found were further validated by a new independent amplification and sequencing.

\section{Statistical analysis}

The $\chi^{2}$-test was used to determine the relationship between each categorical variable and D-Loop mutations, and a $t$-test to determine the relationship between quantitative variables and D-Loop mutations. Survival curves were constructed using the Kaplan-Meier method and compared using the log-rank test. The 
median time of survival was used to summarise the survival data. These statistical tests were performed using the STATA software (STATA 7.0; College Station, TX, USA). A $P$-value $<0.05$ was used to indicate statistical significance.

\section{RESULTS}

\section{Displacement-Loop mutations}

Displacement-Loop sequence analysis was performed in 109 patients. A total of 25 somatic D-Loop mutations were identified in 23 of the $109(21 \%)$ tumours (Table 2). The majority of the mutations were located in the D310 mononucleotide repeat (19 out of $25,76 \%)$. These mutations were insertions or deletions of one $(n=15)$ to several $(n=4)$ base pairs. Six mutations were found outside the D310 sequence. Among them, five were substitution of one base pair. The last one was a CA deletion at the nucleotide position 514. Two patients (nos. 22 and 153) had two mutations: in each of them, a D310 mutation coexisted with a D-Loop mutation located outside the D310 repeat. Among all mutations, 10 (40\%) were homoplasmic and $15(60 \%)$ were heteroplasmic. Homoplasmic mutations were significantly more frequent in the group of D-Loop mutations located outside the D310 repeat (5/6) than in the group of D310 mutations (five out of 19) ( 83 vs $26 \%, P=0.02$ ).

The D310 sequence is polymorphic in the human population. The number of cytosines in the 7-bp tract varied from 6 to 13 and the most frequent sequences for the $\mathrm{D} 310$ region are $\mathrm{C}_{7} \mathrm{TC}_{6}, \mathrm{C}_{8} \mathrm{TC}_{6}$ and $\mathrm{C}_{9} \mathrm{TC}_{6}$. In our series, the $\mathrm{D} 310$ sequence in nonmalignant tumour tissues was homoplasmic in $83.5 \%$ and heteoplasmic in $16.5 \%$ of the cases and was distributed as follows: $\mathrm{C}_{7} \mathrm{TC}_{6}$ in 65 out of $109(59.6 \%), \mathrm{C}_{8} \mathrm{TC}_{6}$ in 20 out of $109(18.4 \%), \mathrm{C}_{9} \mathrm{TC}_{6}$ in six out of $109(5.5 \%), \mathrm{C}_{8} \mathrm{TC}_{6} / \mathrm{C}_{9} \mathrm{TC}_{6}$ in 17 out of $109(15.6 \%)$ and $\mathrm{C}_{9} \mathrm{TC}_{6} /$ $\mathrm{C}_{10} \mathrm{TC}_{6}$ in one out of $109(0.9 \%)$. The prevalence of tumour D310 mutations increased significantly with the number of cytosines in

Table 2 Summary of D-Loop somatic mutations found in the 109 HNSCC patients

\begin{tabular}{|c|c|c|c|}
\hline $\begin{array}{l}\text { Patients } \\
\text { number }\end{array}$ & $\begin{array}{l}\text { Nucleotide } \\
\text { position }\end{array}$ & DNA $(\mathbf{N} \rightarrow \mathbf{T})^{\mathbf{a}}$ & $\begin{array}{l}\text { MtDNA } \\
\text { mutation status }\end{array}$ \\
\hline 16 & $303-309$ & $\mathrm{C} 7 \rightarrow \mathrm{C} 7 / \mathrm{C} 9$ & Heteroplasmy \\
\hline \multirow[t]{2}{*}{22} & 214 & $A \rightarrow G$ & Homoplasmy \\
\hline & $303-309$ & $\mathrm{C} 8 / \mathrm{C} 9 \rightarrow \mathrm{C} 8$ & Homoplasmy \\
\hline 23 & 514 & $(\mathrm{CA}) 5 \rightarrow(\mathrm{CA}) 4$ & Homoplasmy \\
\hline 28 & 314 & $\mathrm{C} \rightarrow \mathrm{T}$ & Homoplasmy \\
\hline 32 & $303-309$ & $\mathrm{C} 8 \rightarrow \mathrm{C} 7$ & Homoplasmy \\
\hline 42 & $303-309$ & $\mathrm{C} 7 \rightarrow \mathrm{C} 7 / \mathrm{C} 9$ & Heteroplasmy \\
\hline 43 & $303-309$ & $\mathrm{C} 8 / \mathrm{C} 9 \rightarrow \mathrm{C} 8 / \mathrm{ClO}$ & Heteroplasmy \\
\hline 48 & $303-309$ & $\mathrm{C} 8 \rightarrow \mathrm{C} 7 / \mathrm{C} 8$ & Heteroplasmy \\
\hline 53 & $303-309$ & $\mathrm{C} 8 \rightarrow \mathrm{C} 8 / \mathrm{C} 9$ & Heteroplasmy \\
\hline 63 & $303-309$ & $\mathrm{C} 8 / \mathrm{C} 9 \rightarrow \mathrm{C} 8$ & Homoplasmy \\
\hline 82 & $303-309$ & $\mathrm{C} 9 / \mathrm{ClO} \rightarrow \mathrm{C} 9$ & Homoplasmy \\
\hline 110 & $303-309$ & $\mathrm{C} 7 \rightarrow \mathrm{C} 6 / \mathrm{C} 7$ & Heteroplasmy \\
\hline 114 & $303-309$ & $\mathrm{C} 8 / \mathrm{C} 9 \rightarrow \mathrm{C} 9 / \mathrm{ClO}$ & Heteroplasmy \\
\hline 118 & 213 & $A \rightarrow G$ & Homoplasmy \\
\hline 127 & $303-309$ & $\mathrm{C} 8 \rightarrow \mathrm{C} 8 / \mathrm{C} 9$ & Heteroplasmy \\
\hline$|4|$ & $303-309$ & $\mathrm{C} 9 \rightarrow \mathrm{C} 8$ & Homoplasmy \\
\hline 146 & 408 & $\mathrm{~T} \rightarrow \mathrm{A}$ & Heteroplasmy \\
\hline \multirow[t]{2}{*}{153} & 239 & $\mathrm{C} \rightarrow \mathrm{T}$ & Homoplasmy \\
\hline & $303-309$ & $\mathrm{C} 7 \rightarrow \mathrm{C} 9 / \mathrm{ClO}$ & Heteroplasmy \\
\hline 155 & $303-309$ & $\mathrm{C} 8 / \mathrm{C} 9 \rightarrow \mathrm{C} 9$ & Heteroplasmy \\
\hline 161 & $303-309$ & $\mathrm{C} 8 \rightarrow \mathrm{C} 7 / \mathrm{C} 8$ & Heteroplasmy \\
\hline 167 & $303-309$ & $\begin{array}{l}\mathrm{C} 8 / \mathrm{C} 9 \rightarrow \\
\text { complex }\end{array}$ & Heteroplasmy \\
\hline 180 & $303-309$ & $\mathrm{C} 9 \rightarrow \mathrm{C} 8 / \mathrm{C} 9$ & Heteroplasmy \\
\hline 206 & $303-309$ & $\mathrm{C} 8 \rightarrow \mathrm{C} 8 / \mathrm{C} 9$ & Heteroplasmy \\
\hline
\end{tabular}

${ }^{a} \mathrm{~N}=$ normal tissue; $\mathrm{T}=$ tumour tissue. $\mathrm{HNSCC}=$ head and neck squamous cell carcinoma; D-Loop = Displacement-Loop. the matched normal tissue sequence. Indeed, the $\mathrm{C}_{7} \mathrm{TC}_{6}$ sequence was altered in eight patients out of the $65(12 \%)$, the $\mathrm{C}_{8} \mathrm{TC}_{6}$ and $\mathrm{C}_{8} \mathrm{TC}_{6} / \mathrm{C}_{9} \mathrm{TC}_{6}$ sequences were altered in 12 patients out of the 37 $(32 \%)$ and the $\mathrm{C}_{9} \mathrm{TC}_{6}$ and $\mathrm{C}_{9} \mathrm{TC}_{6} / \mathrm{C}_{10} \mathrm{TC}_{6}$ sequences were altered in three out of the seven cases $(43 \%)(P=0.02)$.

A total of 24 germline polymorphisms were found (Table 3 ). Twenty-one were already reported in the MITOMAP database and three of them (A240G, A249G and C534T) are novel.

\section{Association of D-Loop mutations and clinicopathologic characteristics}

The analysis of clinicopathologic variables showed a significant difference in tumour site between tumours with and without D-Loop mutation $(P=0.03)$. Indeed, among $D$-Loop-mutated tumours, $47.8 \%$ were located in the hypopharynx as compared to $18.6 \%$ in the group of nonmutated tumours (Table 1). Moreover, presence of D-Loop mutation was significantly associated with tobacco consumption: the mean number of pack-year in the group of patients with tumour D-Loop mutation was $48 \pm 3$ compared to $37 \pm 2$ for patients without mutation $(P=0.01)$. The analysis of other clinicopathologic variables showed no correlation between the presence of a tumour D-Loop mutation and, respectively, age, gender, tumour stage and TP53 mutation (Table 1).

\section{Association of D-Loop mutations and response to chemotherapy and survival}

Tumours were classified according to the decrease in tumour size after 5FU-cisplatin-based chemotherapy as it was defined in the Materials and Methods section. In all, 72 patients (66.1\%) were

Table 3 Summary of the germline polymorphisms found in the 109 head and neck squamous cell carcinoma patients

\begin{tabular}{|c|c|c|c|}
\hline Patients number & $\begin{array}{l}\text { Nucleotide } \\
\text { substitution }\end{array}$ & $\begin{array}{l}\text { Nucleotide } \\
\text { position }\end{array}$ & $\begin{array}{l}\text { Reported } \\
\text { polymorphism } \\
\left(\text { database }^{\text {a }}\right)\end{array}$ \\
\hline 16,53 & $G \rightarrow A$ & 200 & Yes \\
\hline $20,48,206$ & $\mathrm{~T} \rightarrow \mathrm{C}$ & 204 & Yes \\
\hline 48,206 & $G \rightarrow A$ & 207 & Yes \\
\hline $27,32,52,128,150$ & $G \rightarrow A$ & 228 & Yes \\
\hline 82 & $\mathrm{~T} \rightarrow \mathrm{C}$ & 239 & Yes \\
\hline 199 & $A \rightarrow G$ & 240 & Novel \\
\hline $41,54,171$ & $C \rightarrow T$ & 242 & Yes \\
\hline 133 & $A \rightarrow G$ & 249 & Novel \\
\hline 48 & $\mathrm{~T} \rightarrow \mathrm{C}$ & 250 & Yes \\
\hline 44 & $A \rightarrow G$ & 257 & Yes \\
\hline 171 & $C \rightarrow T$ & 295 & Yes \\
\hline $\begin{array}{l}9,13,18,26,31,35,65,72, \\
76,84,87,88,116,164 \\
169,177,183,190\end{array}$ & $\mathrm{C} 7 \rightarrow \mathrm{C} 8$ & $303-309$ & Yes \\
\hline $20,133,156,159$ & $\mathrm{C} 7 \rightarrow \mathrm{C} 9$ & $303-309$ & Yes \\
\hline 22 & $C \rightarrow T$ & 456 & Yes \\
\hline $28,32,41,52,54,|28,17|$ & $C \rightarrow T$ & 462 & Yes \\
\hline 44,119 & $T \rightarrow C$ & 477 & Yes \\
\hline $\begin{array}{l}28,32,41,52,54,128,171 \\
172\end{array}$ & $\mathrm{~T} \rightarrow \mathrm{C}$ & 489 & Yes \\
\hline $26,83,194,208$ & $C \rightarrow T$ & 497 & Yes \\
\hline 47 & $A \rightarrow C$ & 512 & Yes \\
\hline $\begin{array}{l}23,32,71,72,83,130,146 \\
172,195\end{array}$ & $\begin{array}{l}(\mathrm{CA}) 5 \rightarrow \\
(\mathrm{CA}) 4\end{array}$ & 514 & Yes \\
\hline 192 & $\begin{array}{l}(\mathrm{CA}) 5 \rightarrow \\
(\mathrm{CA}) 6\end{array}$ & 514 & Yes \\
\hline 9,22 & $\begin{array}{l}\text { (CA) } 5 \rightarrow \\
(C A) 7\end{array}$ & 514 & Yes \\
\hline 65 & $A \rightarrow G$ & 533 & Yes \\
\hline 165 & $\mathrm{C} \rightarrow \mathrm{T}$ & 534 & Novel \\
\hline
\end{tabular}

aMITOMAP database available on web: www.mitomap.org. 


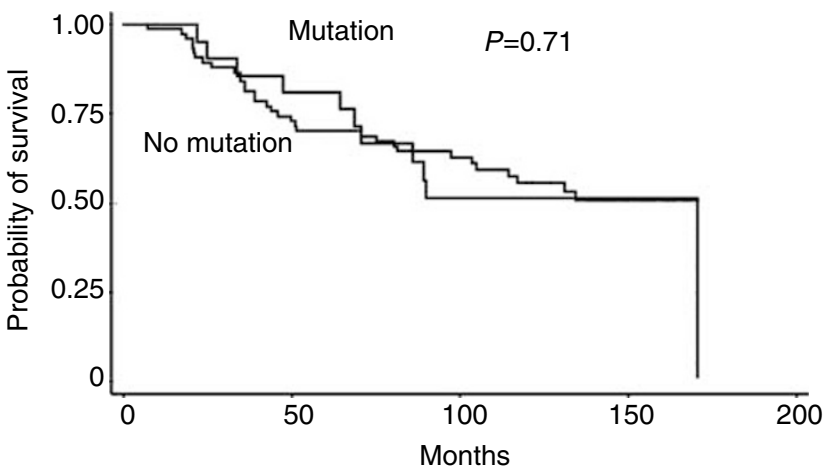

Figure I Overall survival curves of HNSCC patients with and without tumour D-Loop mutation.

responders and $37(33.9 \%)$ were nonresponders. No correlation was found between the presence of tumour D-Loop mutation and response to neoadjuvant chemotherapy (Table 1).

The presence of D-Loop mutation was not a prognostic factor: the 5-year overall survival of patients with tumour D-Loop mutation was $81 \%$ compared to $70 \%$ for patients without mutation $(P=0.71$, Figure 1$)$.

\section{DISCUSSION}

In the past few years, somatic mtDNA mutations have been identified in several types of human tumours (Polyak et al, 1998; Fliss et al, 2000; Maximo et al, 2000; Richard et al, 2000; Yeh et al, 2000; Hibi et al, 2001b; Kirches et al, 2001; Liu et al, 2001; SanchezCespedes et al, 2001; Nomoto et al, 2002; Lievre et al, 2005), including HNSCC (Fliss et al, 2000; Sanchez-Cespedes et al, 2001; Ha et al, 2002; Poetsch et al, 2004). In the present study, which is the largest series of HNSCC analysed for mtDNA mutations in the literature, we report a $21 \%$ frequency of D-Loop somatic mutations. This frequency is similar to that obtained by Fliss et al (2000) who performed a sequence analysis of $80 \%$ of the mitochondrial genome and found a D-Loop mutation in three of $13(23 \%)$ HNSCC patients. However, other studies on small series of patients reported more frequent D-Loop mutations, ranging from 37 to $61 \%$ (Sanchez-Cespedes et al, 2001; Ha et al, 2002; Poetsch et al, 2004) of the cases. In these studies, D310 repeat emerged as a mutational hotspot. On 67 primary HNSCC from 56 patients, Poetsch et al (2004) sequenced two parts of the D-Loop and two mitochondrial genes (MTND1 and MTND5). They found all mtDNA mutations in a part of the D-Loop and a mtDNA microsatellite instability, defined as insertions or deletions in the D310 repeat, in $42 \%$ of the tumours. Another study showed $66 \%$ of D-Loop mutations in 18 oral cancers of betel quid chewers (Tan et al, 2003), which however cannot be really assimilated to HNSCC of tobacco and alcohol consumers. The vast majority of these mutations were located between nucleotides 204 and 489 and $44 \%$ of the tumours harboured mutations in the D310 repeat. These results led us to focus our sequence analysis on a $400 \mathrm{bp}$ fragment of the D-Loop (nucleotide position: 190-490) containing the D310 C-tract which was found to be a hotspot of mutations since more than $80 \%$ of the D-Loop mutations were located in this sequence, as it was suggested previously (Sanchez-Cespedes et al, 2001; Ha et al, 2002). The differences in D-Loop mutation frequency observed between our study, that of Fliss et al and the other studies remain to be explained. Overestimation of gene mutation rates is frequently observed in series of small sample size, which is the case of previous studies that have specifically addressed the D-Loop mutation frequency issue in HNSCC. As a consequence, our study gives new information as regards to the frequency of
D-Loop mutations in HNSCC that has likely been overestimated in previous studies of small samples size. Another explanation may be differences in distribution of tumour sites between studies. We showed that tumours located in the hypopharynx $(24.8 \%$ of all tumours) were significantly more mutated than tumours in other sites. Proportion of hypopharynx tumours is not known in the other studies (Fliss et al, 2000; Sanchez-Cespedes et al, 2001; Ha et al, 2002; Poetsch et al, 2004). So, we can speculate that a higher proportion of tumours located in the hypopharynx would be associated with a higher frequency of mtDNA mutation. Moreover, in the present study, the prevalence of tumour D310 mutations increased significantly with the number of cytosines in the D310 sequence of matched normal tissues. According to these findings, the frequency of D-Loop mutations may depend on the proportion of the different $\mathrm{D} 310$ sequences in the normal tissues $\left(\mathrm{C}_{7-8-9-10} \mathrm{TC}_{6}\right)$, which is probably not the same in the different studies. Finally, the mtDNA mutagenesis process in oral squamous cell carcinoma of betel quid chewers is likely to be different to that of cigarettes smokers. Betel quid contains tender areca nuts and lime that have been shown to generate ROS and induce oxidative DNA damage (Nair et al, 1987; Stich and Anders, 1989), which can initiate or promote oral carcinogenesis. These betel quid compounds could therefore preferentially target mtDNA, which may explain the high proportion of oral tumours with mtDNA mutation observed in betel quid chewers (Tan et al, 2003), compared to that observed in cigarette smokers.

With a frequency of more than $20 \%$ in HNSCC, D-Loop mutations may be an interesting molecular marker in the evaluation of the tumorigenic potential of head and neck lesions in individuals at high risk of this cancer. They were shown to be an early event in head and neck carcinogenesis (Ha et al, 2002). Their frequence was $22 \%$ in the earliest head and neck premalignant lesions and increased with the degree of dysplasia to reach $50 \%$ in lesions of severe dysplasia and $61 \%$ in carcinomas in situ in a recent study (Ha et al, 2002). Similar results were obtained in prostate (Jeronimo et al, 2001) and oesophagus adenocarcinoma (Miyazono et al, 2002) where identical D-Loop mutations were found both in primary tumours and corresponding premalignant lesions, which is consistent with a process of clonal evolution. These data suggest that D-Loop mutations could be considered as a cancer biomarker that may be useful for the early detection of HNSCC. It is all the more important since mtDNA mutations were reported to be easily detectable in bodily fluids and serum of cancer patients (Fliss et al, 2000; Hibi et al, 2001a; Jeronimo et al, 2001; Parrella et al, 2001; Nomoto et al, 2002). As a consequence, it would be interesting to search for D-Loop mutations in saliva and serum of a large series of HNSCC patients in order to evaluate their relevance in association with other tumour-specific molecular alterations in the screening of this cancer in alcohol and tobacco consumers.

We analysed for the first time the correlation between mtDNA mutations and clinicopathologic characteristics in a series of HNSCC patients. We found that tobacco consumption was significantly more important in the group of patients with tumour D-Loop mutation than in those without mutation. It is not very surprising since cigarette smoke contains several mutagenic ROS-forming subtances and carcinogens that can cause DNA damages, especially in mtDNA that has been proved to be more susceptible to oxidative damages than nDNA (Marcelino and Thilly, 1999). In the same way, mtDNA content alterations have been recently shown to be associated with smoking (Ballinger et al, 1996; Lee et al, 1998). Our results also show an association between tumour site and D-Loop mutation, demonstrating that hypopharyngeal tumours were significantly more frequent in the group of mutated tumours compared to that of nonmutated tumours. This association remains unclear. One explanation could be a difference in exposition degree to mtDNA mutagenic agents between hypopharynx and other tumour sites. It was shown a 
696

significant higher risk for cancer of the hypopharynx than for larynx cancer with alcohol drinking, which may be explained by the fact that hypopharynx enters in contact with the bolus (alcohol) and the air (tobacco smoke) while air pass through larynx but not the bolus (Esteve et al, 1996; Menvielle et al, 2004). Alcohol is known to cause oxidative stress through production of ROS (Hoek et al, 2002) and ethanol consumption has been reported to induce oxidative damage to mtDNA with increased levels of 8-hydroxydeoxyguanosin in rats (Cahill et al, 1997). The abasic sites and oxidised bases generated could so be responsible for mtDNA mutations. We did not found any correlation between $\mathrm{D}$-Loop mutation and gender. This may be explained by the disequilibrium between the group of male $(n=98)$ and female $(n=11)$ subjects. A better distribution between gender would have been desirable but is not possible to obtain in practice since the sex ratio currently observed in France for HNSCC is approximately M:7/F:1.

In the present study, our first intention was not to investigate the prognostic value of D-Loop mutations and their association with response to chemotherapy, but to evaluate their role as a biomarker of HNSCC by determining the real frequency in HNSCC and their potential correlation with clinicopathologic parameters. However, neoadjuvant chemotherapy has been recently developed in locally advanced HNSCC because conventional treatments with radiotherapy and surgery do not always control them, are associated with profound functional morbidity and often result in physical and psychological suffering. Cisplatin and 5FU combination, which is the standard regimen in this case, has shown objective response rates of $71 \%$, with complete response rates of $18 \%$ (Altundag et al, 2005). This neoadjuvant chemotherapy do not improve survival but is of interest in terms of organ preservation strategies in responder patients (Laccourreye et al, 1999) and has been shown to be curative in complete clinical responder patients with a cancer of the pharyngolarynx (Laccourreye et al, 2001). Therefore, identification of factors linked to response to neoadjuvant chemotherapy in HNSSC may help in the selection of patients who could benefit from an organ preservation. Some studies have revealed that the drug-resistance phenotype can be significantly associated with resistance to apoptosis induced by drugs (Landowski et al, 1997). Mitochondria is known to play a pivotal role in apoptosis (Green and Kroemer, 2004), and it was

\section{REFERENCES}

Altundag O, Gullu I, Altundag K, Yalcin S, Ozyar E, Cengiz M, Akyol F, Yucel T, Hosal S, Sozeri B (2005) Induction chemotherapy with cisplatin and 5-fluorouracil followed by chemoradiotherapy or radiotherapy alone in the treatment of locoregionally advanced resectable cancers of the larynx and hypopharynx: results of single-center study of 45 patients. Head Neck 27: 15-21

Ballinger SW, Bouder TG, Davis GS, Judice SA, Nicklas JA, Albertini RJ (1996) Mitochondrial genome damage associated with cigarette smoking. Cancer Res 56: $5692-5697$

Blons H, Cabelguenne A, Carnot F, Laccourreye O, de Waziers I, Hamelin R, Brasnu D, Beaune P, Laurent-Puig P (1999) Microsatellite analysis and response to chemotherapy in head-and-neck squamous-cell carcinoma. Int J Cancer 84: $410-415$

Blons H, Gad S, Zinzindohoue F, Maniere I, Beauregard J, Tregouet D, Brasnu D, Beaune P, Laccourreye O, Laurent-Puig P (2004) Matrix metalloproteinase 3 polymorphism: a predictive factor of response to neoadjuvant chemotherapy in head and neck squamous cell carcinoma. Clin Cancer Res 10: 2594-2599

Cahill A, Wang X, Hoek JB (1997) Increased oxidative damage to mitochondrial DNA following chronic ethanol consumption. Biochem Biophys Res Commun 235: 286-290

Esteve J, Riboli E, Pequignot G, Terracini B, Merletti F, Crosignani P, Ascunce N, Zubiri L, Blanchet F, Raymond L, Repetto F, Tuyns AJ (1996) Diet and cancers of the larynx and hypopharynx: the IARC multi-center study in southwestern Europe. Cancer Causes Control 7: 240-252 suggested that mtDNA determines the cellular response to some cancer therapeutic agents through a mechanism that could be an apoptosis modulation (Singh et al, 1999; Hail et al, 2001). We recently found that D-Loop mutations were associated with poor prognosis and absence of benefit from adjuvant 5FU chemotherapy in colon cancers (Lievre et al, 2005). Given these results, as all patients in our study received a neoadjuvant chemotherapy with 5FU-cisplatin, we investigated the association between DLoop mutations and response to this treatment. No association with prognosis or with response to 5FU-cisplatin was found. These results suggest that mtDNA do not play the same role in the cytotoxicity of these two anticancer drugs. As 5FU interferes with the apoptotic process (Sakaguchi et al, 1994), we hypothesised in our previous study (Lievre et al, 2005) that the potential respiratory chain alteration induced by D-Loop mutations could explain in part the absence of benefit from 5FU we observed. On the contrary, Liang et al demonstrated that mtDNA depletion increased the sensitivity of cisplatin-induced apoptosis in U937 cells when compared to parental controls containing mtDNA (Liang and Ullyatt, 1998). According to these findings, we can speculate that D-Loop mutations may lead both to resistance to $5 \mathrm{FU}$ and increased sensitivity to cisplatin, which may explain that no link was observed between these mutations and response to the combined therapy in the present study. However, the power of our study remains low as regards to the small sample size and the unequal distribution of patients into the two groups considered for the analysis (23 tumours with D-Loop mutations, 86 tumours without), and larger studies are needed to confirm this result.

In conclusion, our data suggest that D-Loop mutations should be considered as a cancer biomarker that may be useful for the early detection of HNSCC in individuals at risk of this cancer. The presence of these mutations in saliva and serum of tobacco and alcohol consumers should be investigated in further studies in order to evaluate their relevance in the screening of these cancers in association with other tumour-specific molecular alterations.

\section{ACKNOWLEDGEMENTS}

This study has been supported by La Ligue Nationale de Lutte Contre le Cancer.

Fliss MS, Usadel H, Caballero OL, Wu L, Buta MR, Eleff SM, Jen J, Sidransky D (2000) Facile detection of mitochondrial DNA mutations in tumors and bodily fluids. Science 287: 2017-2019

Green DR, Kroemer G (2004) The pathophysiology of mitochondrial cell death. Science 305: 626-629

Ha PK, Tong BC, Westra WH, Sanchez-Cespedes M, Parrella P, Zahurak M, Sidransky D, Califano JA (2002) Mitochondrial C-tract alteration in premalignant lesions of the head and neck: a marker for progression and clonal proliferation. Clin Cancer Res 8: $2260-2265$

Hail Jr N, Youssef EM, Lotan R (2001) Evidence supporting a role for mitochondrial respiration in apoptosis induction by the synthetic retinoid CD437. Cancer Res 61: 6698-6702

Hibi K, Nakayama H, Yamazaki T, Takase T, Taguchi M, Kasai Y, Ito K, Akiyama S, Nakao A (2001a) Detection of mitochondrial DNA alterations in primary tumors and corresponding serum of colorectal cancer patients. Int J Cancer 94: 429-431

Hibi K, Nakayama H, Yamazaki T, Takase T, Taguchi M, Kasai Y, Ito K, Akiyama S, Nakao A (2001b) Mitochondrial DNA alteration in esophageal cancer. Int J Cancer 92: 319-321

Hoek JB, Cahill A, Pastorino JG (2002) Alcohol and mitochondria: a dysfunctional relationship. Gastroenterology 122: 2049-2063

Jeronimo C, Nomoto S, Caballero OL, Usadel H, Henrique R, Varzim G, Oliveira J, Lopes C, Fliss MS, Sidransky D (2001) Mitochondrial mutations in early stage prostate cancer and bodily fluids. Oncogene 20: $5195-5198$ 
Kirches E, Krause G, Warich-Kirches M, Weis S, Schneider T, MeyerPuttlitz B, Mawrin C, Dietzmann K (2001) High frequency of mitochondrial DNA mutations in glioblastoma multiforme identified by direct sequence comparison to blood samples. Int J Cancer 93: 534-538

Laccourreye O, Bassot V, Brasnu D, Laccourreye H (1999) Chemotherapy combined with conservation surgery in the treatment of early larynx cancer. Curr Opin Oncol 11: 200-203

Laccourreye O, Veivers D, Hans S, Menard M, Brasnu D, Laccourreye H (2001) Chemotherapy alone with curative intent in patients with invasive squamous cell carcinoma of the pharyngolarynx classified as T1T4N0M0 complete clinical responders. Cancer 92: 1504-1511

Landowski TH, Gleason-Guzman MC, Dalton WS (1997) Selection for drug resistance results in resistance to Fas-mediated apoptosis. Blood 89: $1854-1861$

Lee HC, Lu CY, Fahn HJ, Wei YH (1998) Aging- and smoking-associated alteration in the relative content of mitochondrial DNA in human lung. FEBS Lett 441: $292-296$

Liang BC, Ullyatt E (1998) Increased sensitivity to cis-diamminedichloroplatinum induced apoptosis with mitochondrial DNA depletion. Cell Death Differ 5: 694-701

Lievre A, Chapusot C, Bouvier AM, Zinzindohoue F, Piard F, Roignot P, Arnould L, Beaune P, Faivre J, Laurent-Puig P (2005) Clinical value of mitochondrial mutations in colorectal cancer. J Clin Oncol 23: $3517-3525$

Liu VW, Shi HH, Cheung AN, Chiu PM, Leung TW, Nagley P, Wong LC, Ngan HY (2001) High incidence of somatic mitochondrial DNA mutations in human ovarian carcinomas. Cancer Res 61: 5998-6001

Marcelino LA, Thilly WG (1999) Mitochondrial mutagenesis in human cells and tissues. Mutat Res 434: 177-203

Maximo V, Soares P, Machado JC, Seruca R, Sobrinho-Simoes M (2000) Mitochondrial DNA alteration in gastric cancer. Gastroenterology 119: $1808-1809$

Menvielle G, Luce D, Goldberg P, Bugel I, Leclerc A (2004) Smoking, alcohol drinking and cancer risk for various sites of the larynx and hypopharynx. A case-control study in France. Eur J Cancer Prev 13: $165-172$

Miyazono F, Schneider PM, Metzger R, Warnecke-Eberz U, Baldus SE, Dienes HP, Aikou T, Hoelscher AH (2002) Mutations in the mitochondrial DNA D-Loop region occur frequently in adenocarcinoma in Barrett's esophagus. Oncogene 21: $3780-3783$

Muir C, Weiland L (1995) Upper aerodigestive tract cancers. Cancer 75: $147-153$

Nair UJ, Floyd RA, Nair J, Bussachini V, Friesen M, Bartsch H (1987) Formation of reactive oxygen species and of 8-hydroxydeoxyguanosine in DNA in vitro with betel quid ingredients. Chem Biol Interact 63: 157-169

Nawroz H, van der Riet P, Hruban RH, Koch W, Ruppert JM, Sidransky D (1994) Allelotype of head and neck squamous cell carcinoma. Cancer Res 54: $1152-1155$
Nomoto S, Yamashita K, Koshikawa K, Nakao A, Sidransky D (2002) Mitochondrial D-loop mutations as clonal markers in multicentric hepatocellular carcinoma and plasma. Clin Cancer Res 8: 481-487

Parrella P, Xiao Y, Fliss M, Sanchez-Cespedes M, Mazzarelli P, Rinaldi M, Nicol T, Gabrielson E, Cuomo C, Cohen D, Pandit S, Spencer M, Rabitti C, Fazio VM, Sidransky D (2001) Detection of mitochondrial DNA mutations in primary breast cancer and fine-needle aspirates. Cancer Res 61: $7623-7626$

Poetsch M, Petersmann A, Lignitz E, Kleist B (2004) Relationship between mitochondrial DNA instability, mitochondrial DNA large deletions, and nuclear microsatellite instability in head and neck squamous cell carcinomas. Diagn Mol Pathol 13: 26-32

Polyak K, Li Y, Zhu H, Lengauer C, Willson JK, Markowitz SD, Trush MA, Kinzler KW, Vogelstein B (1998) Somatic mutations of the mitochondrial genome in human colorectal tumours. Nat Genet 20: $291-293$

Richard SM, Bailliet G, Paez GL, Bianchi MS, Peltomaki P, Bianchi NO (2000) Nuclear and mitochondrial genome instability in human breast cancer. Cancer Res 60: 4231 - 4237

Sakaguchi Y, Stephens LC, Makino M, Kaneko T, Strebel FR, Danhauser LL, Jenkins GN, Bull JM (1994) Apoptosis in normal tissues induced by 5-fluorouracil: comparison between bolus injection and prolonged infusion. Anticancer Res 14: 1489-1492

Sanchez-Cespedes M, Parrella P, Nomoto S, Cohen D, Xiao Y, Esteller M, Jeronimo C, Jordan RC, Nicol T, Koch WM, Schoenberg M, Mazzarelli P, Fazio VM, Sidransky D (2001) Identification of a mononucleotide repeat as a major target for mitochondrial DNA alterations in human tumors. Cancer Res 61: 7015-7019

Singh KK, Russell J, Sigala B, Zhang Y, Williams J, Keshav KF (1999) Mitochondrial DNA determines the cellular response to cancer therapeutic agents. Oncogene 18: $6641-6646$

Stich HF, Anders F (1989) The involvement of reactive oxygen species in oral cancers of betel quid/tobacco chewers. Mutat Res 214: 47-61

Tan DJ, Chang J, Chen WL, Agress LJ, Yeh KT, Wang B, Wong LJ (2003) Novel heteroplasmic frameshift and missense somatic mitochondrial DNA mutations in oral cancer of betel quid chewers. Genes Chromosomes Cancer 37: $186-194$

van der Riet $\mathrm{P}$, Nawroz H, Hruban RH, Corio R, Tokino K, Koch W, Sidransky D (1994) Frequent loss of chromosome 9p21-22 early in head and neck cancer progression. Cancer Res 54: 1156-1158

Warburg O (1956) On the origin of cancer cells. Science 123: $309-314$

Yeh JJ, Lunetta KL, van Orsouw NJ, Moore Jr FD, Mutter GL, Vijg J, Dahia PL, Eng C (2000) Somatic mitochondrial DNA (mtDNA) mutations in papillary thyroid carcinomas and differential mtDNA sequence variants in cases with thyroid tumours. Oncogene 19: $2060-2066$

Zamzami N, Kroemer G (2001) The mitochondrion in apoptosis: how Pandora's box opens. Nat Rev Mol Cell Biol 2: 67-71 